\title{
CLUB DEPORTIVO
}

Diego Caballero Tejeda

Juan José Doñoro de la Muela

Carlos Fernández Martínez

Ramón Fernández Verdejo

Jose Ignacio García Borreguero

\section{UN EMBALSE NO TAN MALO}

\section{El pasado}

Búbal es uno de los muchos pueblos afectados por la necesidad de crear en España embalses lo suficientemente grandes como para abastecer de agua en época de sequía a la población y crear saltos para la producción de energía eléctrica.

Con el embalse de Búbal se cubrieron todas las tierras de pasto del ganado y todas las tierras de cultivo, únicas fuentes de ingreso en este pueblo rural.

Con la expropiación de las tierras de cultivo y pasto, los habitantes tuvieron que hacer uso de la expropiación vo- luntaria de sus bienes inmudables (casas, bordas, etc.) teniendo que "emigrar» a pueblos industrializados de la comarca. Esta fue la única salida ante la expropiación.

El pueblo quedó definitivamente abandonado, expuesto a saqueos y desmanes desgraciadamente muy propios en estos casos.

\section{El presente}

Una vez terminados los estudios de arquitectura técnica, se lleva a cabo un Proyecto de Fin de Carrera.

Tras muchas inquietudes, hasta que nos confirmaron el viaje a Búbal, hicimos éste, permaneciendo quince días en dicho lugar.

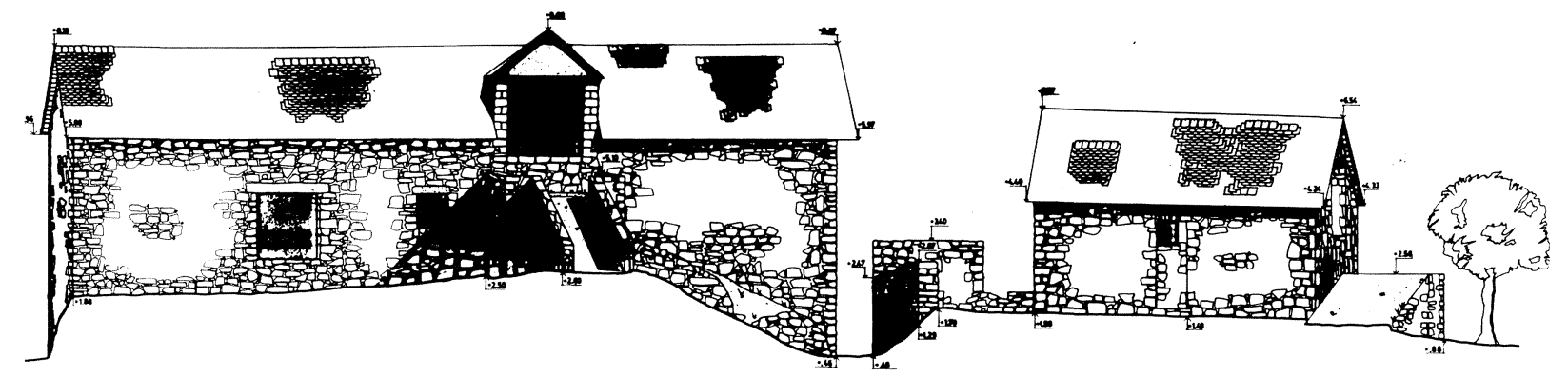

\section{Alzado suroeste}

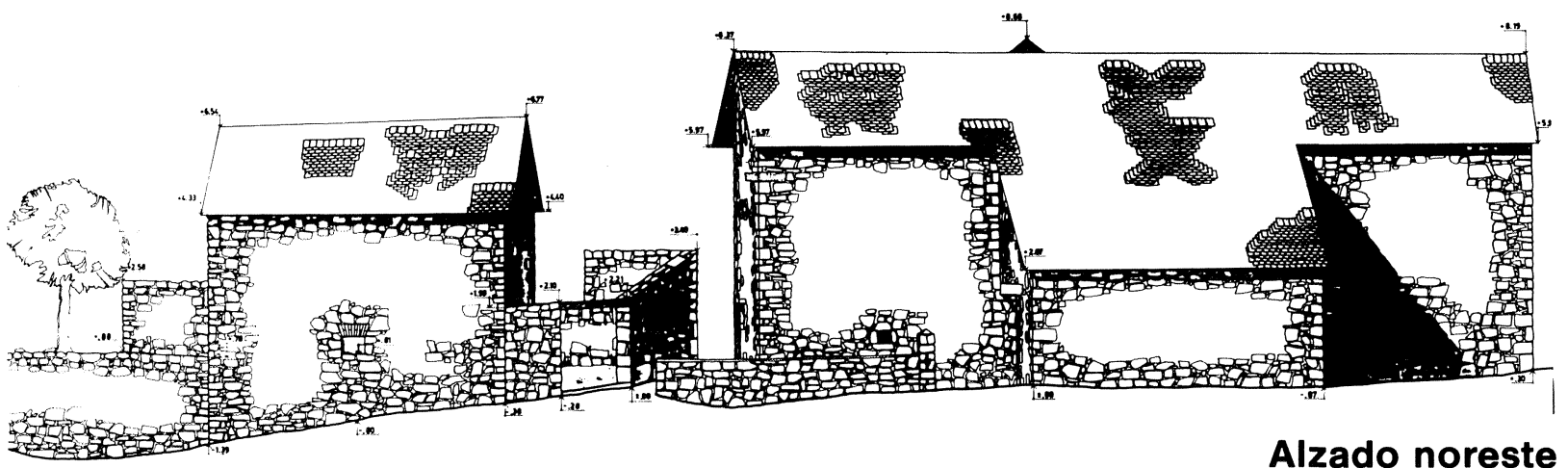




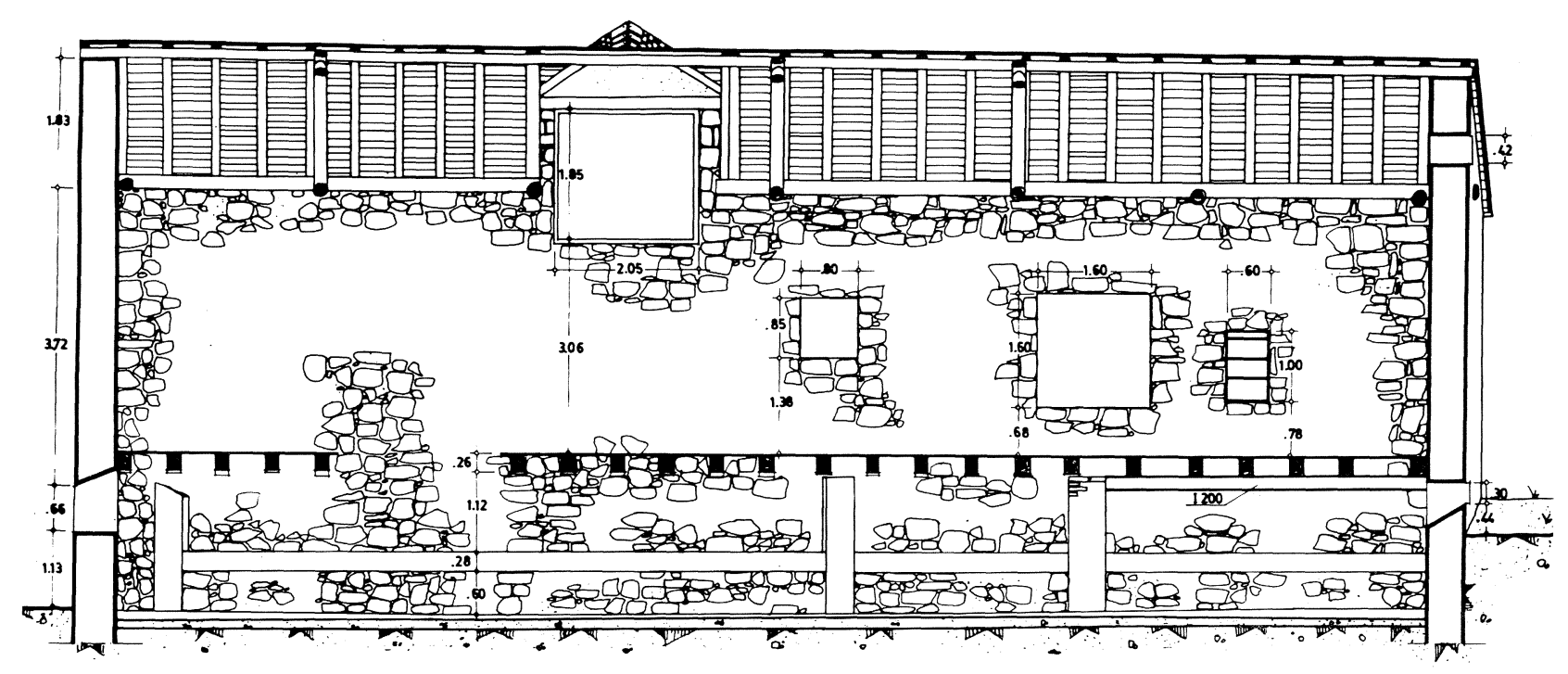

\section{Sección 1-1'}

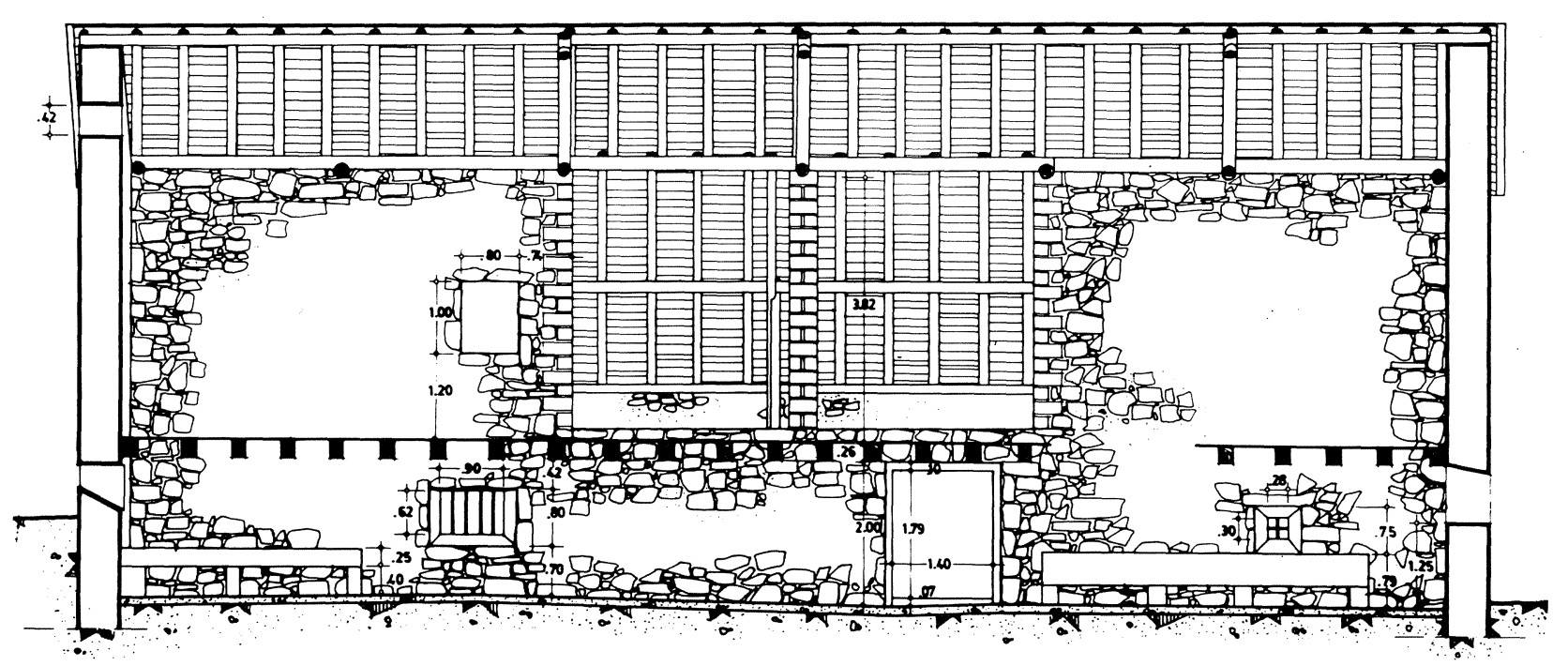

\section{Sección 2-2'}

Antes de salir de Madrid se nos asignó la realización del proyecto de un club náutico. En principio, sin ningún otro dato.

En la actualidad, el futuro club deportivo consta de dos bordas. En Huesca se les llama bordas a los recintos, normalmente de dos plantas, en donde se guardaba al ganado y se almacenaba el pasto respectivamente en planta baja y primera.

Son construcciones de mamposteria tomada con un mortero muy pobre. Cimentación en tierra arcillosa sobre piedra.

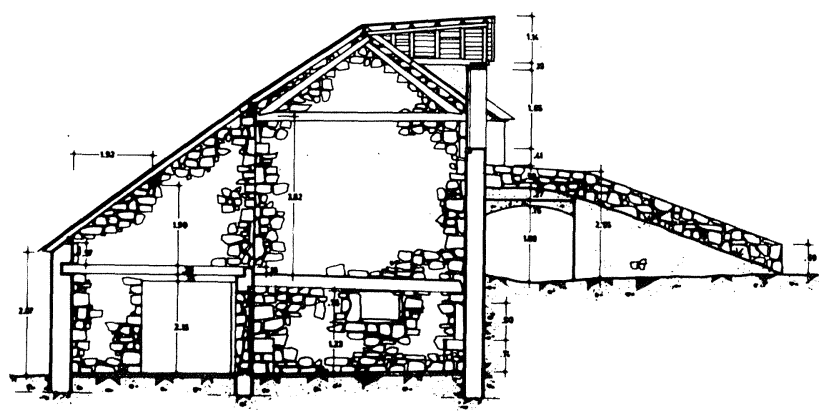




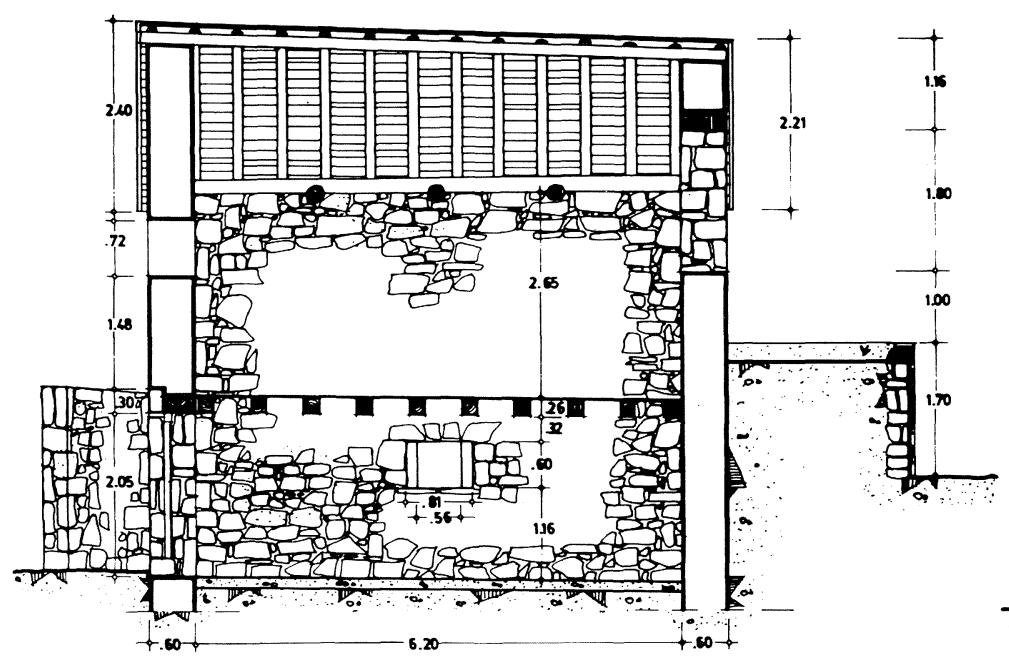

Sección 4-4'

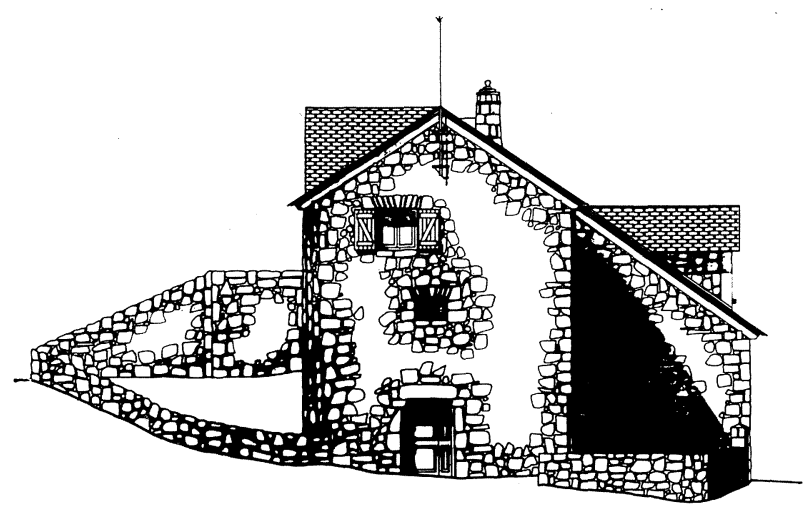

Alzado noroeste

El grosor de los muros oscilaba entre 45 y $55 \mathrm{~cm}$. La estructura de forjados y cubierta es de madera de pino del país.

Los forjados son construidos a base de vigas de madera introducidas en los muros mediante mechinales y sobre éstos un entablado cubierto con pasto que servía de piso y sustentación para el almacenamiento de la comida de los animales.

En la planta baja, donde guardaban los animales, el piso era a base de losas de piedras que posteriormente cubrieron con hormigón con una pequeña canalización para evacuación de posibles filtraciones de agua y desperdicios de los animales.

La cubierta está construida en base a cuatro piezas fundamentales: hilera, zapata, cercha y parecillos.

Las zapateras apoyan sobre los muros. Los tirantes de la cercha de tijera van por debajo de las zapateras y los parecillos apoyan en las zapateras. La hilera apoya sobre

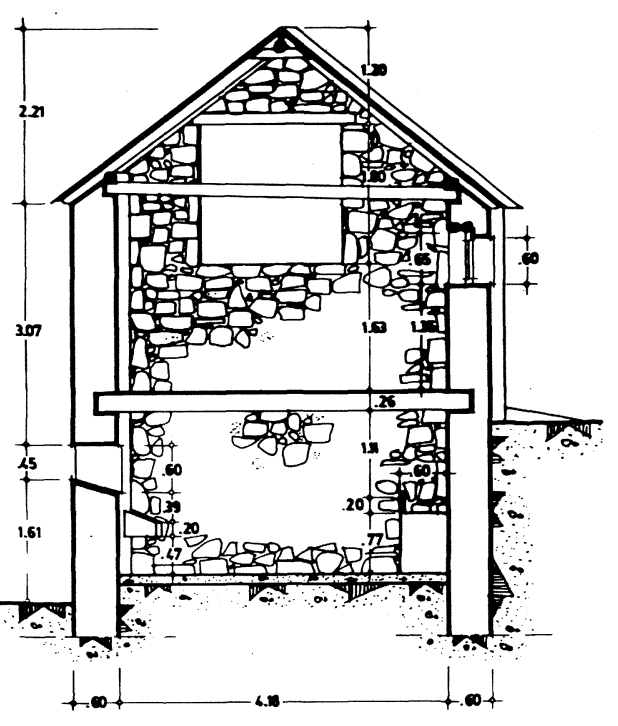

Sección 5-5

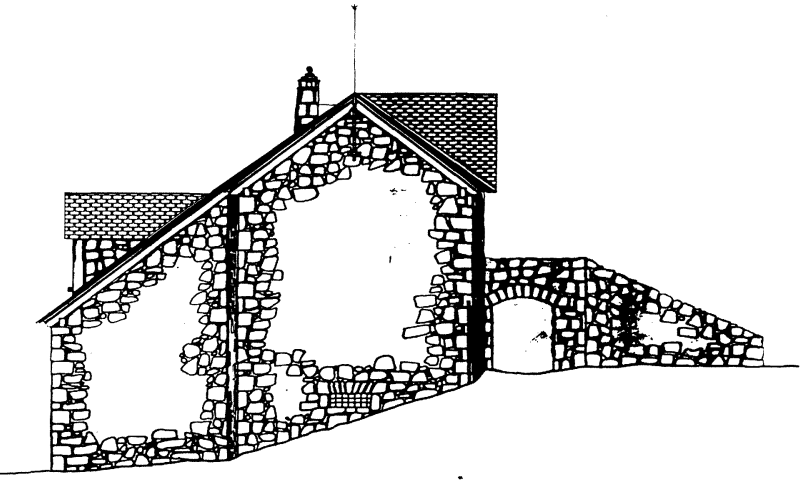

Alzado suroeste

las cerchas. Toda esta estructura está cubierta por un entablado de madera sobre el que se clavan las pizarras de la cobertura.

Como característica principal del estilo arquitectónico hay que señalar el subidero a la parte superior de la borda. Es un elemento típico de la estructura de la borda, apareciendo una tronera a modo de buhardilla y asi facilitando el acceso a la parte superior.

Debido al uso de la borda la ventilación es escasa con dos ventanas en la parte superior aparte de la tronera y en la parte inferior una entrada, posteriormente convertida en ventana tras la construcción del adosado. El adosado es un elemento posterior a la propia edificación con el fin de agrandar el espacio vital del ganado.

Hay que destacar el detalle del subidero en la borda pequeña, ya que el acceso en este edificio no se hace por la parte de la pendiente de la cubierta, como en la borda grande, sino por la zona del hastial, aprovechando la altura de éste para abrir el hueco de acceso a la parte superior de la borda. 
En el interior y a ambos lados, la borda lleva adosados una serie de pesebres, hechos con cemento, que servian de abrevadero para los animales.

El estado actual de los edificios no es penoso, ya que son construcciones sólidas y no muy antiguas.

El abandono de los inmuebles, lleva consigo pequeñas averías que al no ser reparadas se van acrecentando y afectando al conjunto.
El caso más normal es lá rotura de los elementos de cubrimiento (pizarras) permitiendo el paso de la humedad y del agua al interior, en donde a lo largo del tiempo van atacando la madera hasta pudrirla.

Hay que tener en cuenta que los edificios están en un rellano a media ladera y que las filtraciones de agua en la parte alta de las bordas, cuando hay lluvias, son abundantes, llegando a rezumar agua a modo de un manantial por entre las piedras.
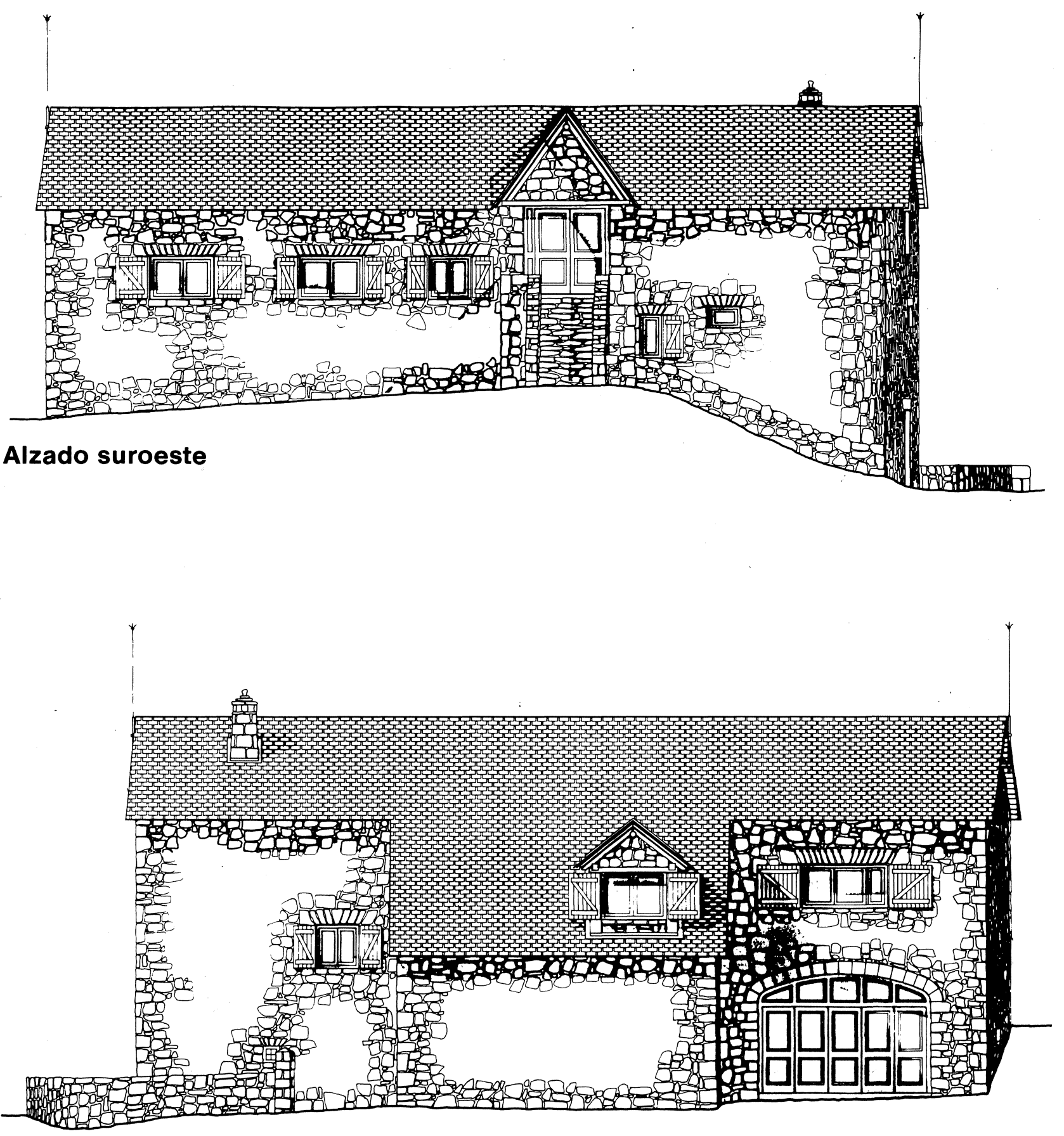

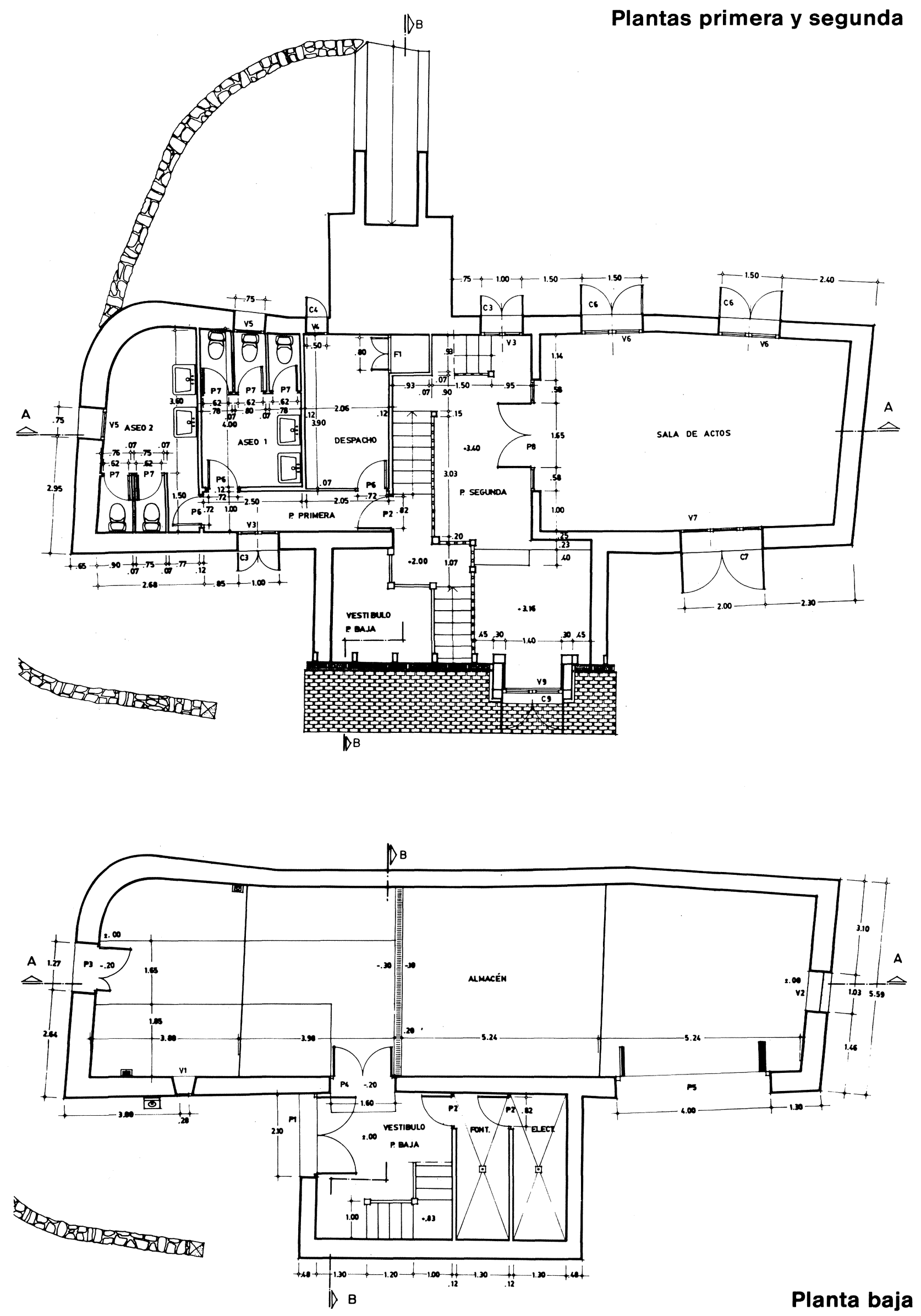


\section{El futuro}

El trabajo a realizar consiste en transformar los edificios abandonados por la construcción de un embalse, en un club deportivo y náutico gracias al embalse.

La causa definitiva del abandono de un pueblo se convirtió en el motivo principal de nuestro trabajo.

En un principio las dos bordas habian de ser exclusivamente un club náutico, pero tras varias conversaciones y debido al contorno montañoso del Pirineo Aragonés, nos decidimos por introducir el montañismo y otros deportes en el club.

Como podemos apreciar en la perspectiva axonométrica, la borda grande se ha convertido en un habitáculo de 3 niveles.
El primer estudio que realizamos fue el derribo interior, después de decidir tirar abajo toda la cubierta incluso estructura y la parte de los forjados que aún se mantengan en pie, así como el descombrado, levantamiento de las soleras y el picado y demolido de los pesebres y los bebederos.

Una vez hechos estos trabajos previos se han de rejuntar exterior o interiormente con un mortero bastardo para darle un cierto aspecto y una consolidación al muro de piedra.

Los tres forjados a distintos niveles son unidireccionales, de viguetas prefabricadas recogidas y atadas a un zuncho perimetral de planta.

Cada forjado lleva una losa volada para facilitar la estructura de la escalera y su colocación.

\section{Detalles de entrada por subidero}

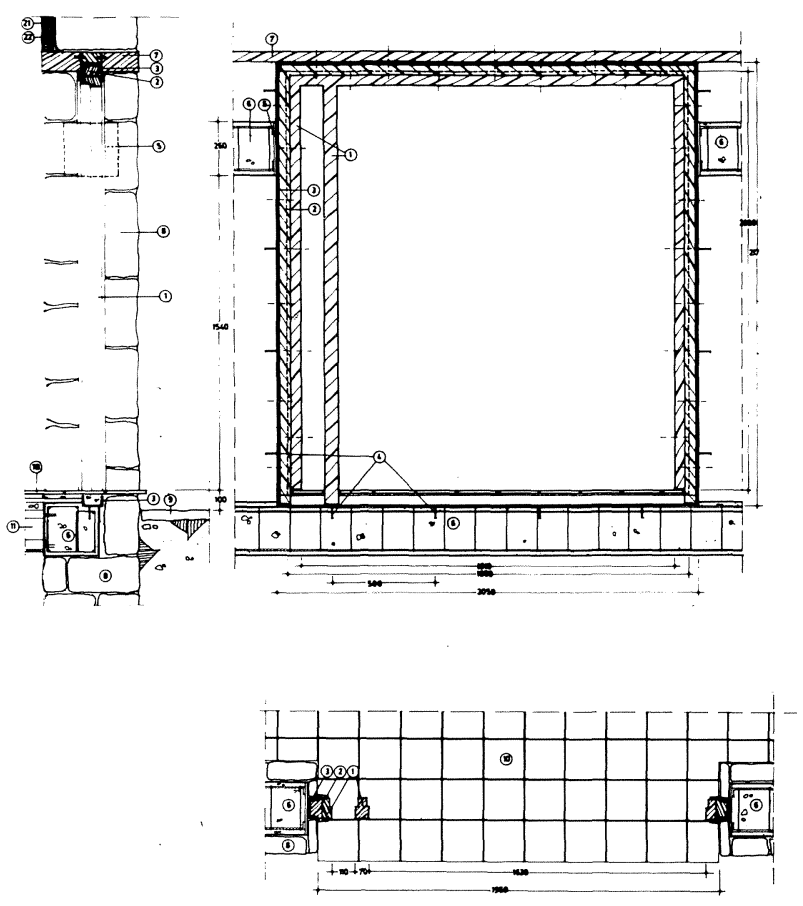

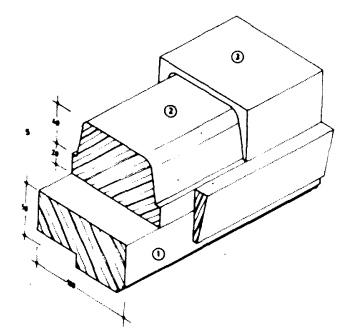

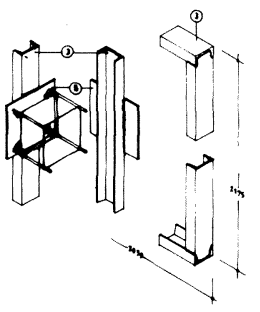

1.- Cerco de madera $100 \times$ 50. 2.-Precerco $100 \times 60$. 3.-UPN 100. 4.Anclajes $\varnothing 100 / 500$. 5. -Placa zuncho $260 \times 260 \times 10$. 6. -Zuncho hormigón armado $260 \times 260$ 7-Dintel 8-Mampostería 9-Enlosado de piedra. 10.-Baldosa cerámica $200 \times 200$. 11.-Forjado unidireccional. 12. - Pizarra $300 \times 300$, solape 200. 13.-Entablado $200 \times 20$. 14.Plancha de cinc. 15.-Rastrel $60 \times 60$. 16.-Aislamiento 60. 17.-Pares $100 \times 100$. 18. - Pares $125 \times 150$. 19.-Hilera $\varnothing 180$. 20.-Hilera $\varnothing 130$. 21.-Entablado $70 \times 10$. 22. - Aislamiento 40. 23. - Tirante $150 \times 150$. 24.-Zapatera $200 \times 150$. 25. - Limatesa $150 \times 150$.

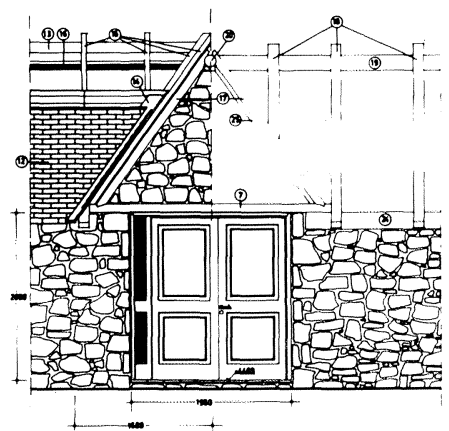

(C) Consejo Superior de Investigaciones Científicas Licencia Creative Commons 3.0 España (by-nc)
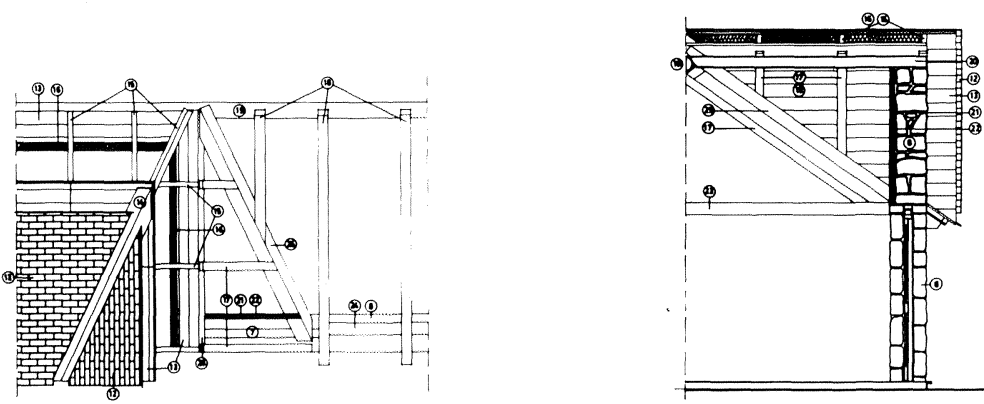

http://informesdelaconstruccion.revistas.csic.es 


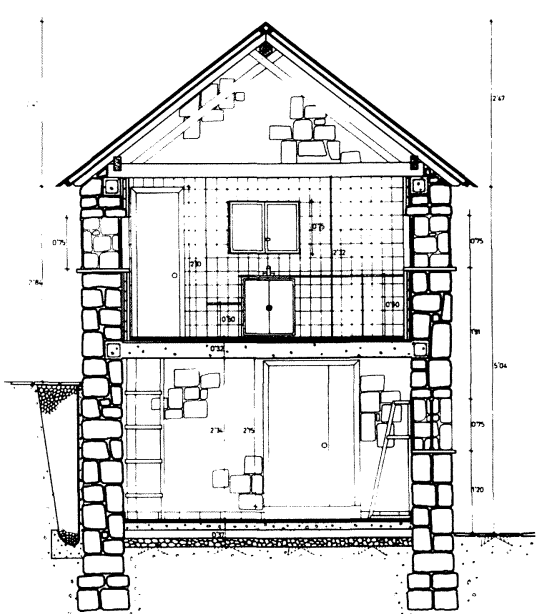

Sección A-A

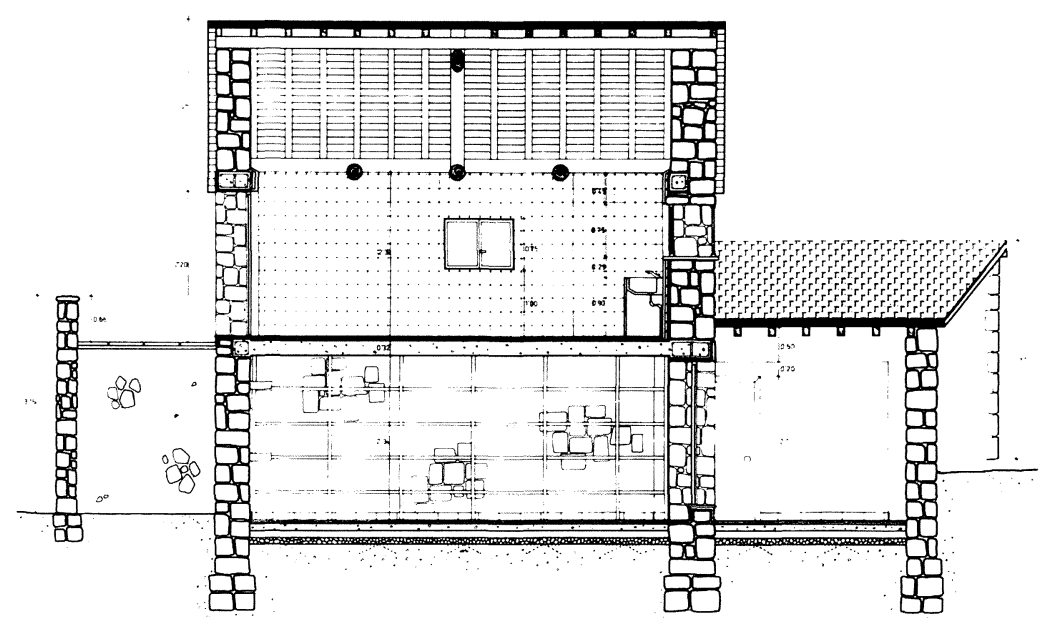

Sección B-B

\section{Secciones borda pequeña (estado futuro)}

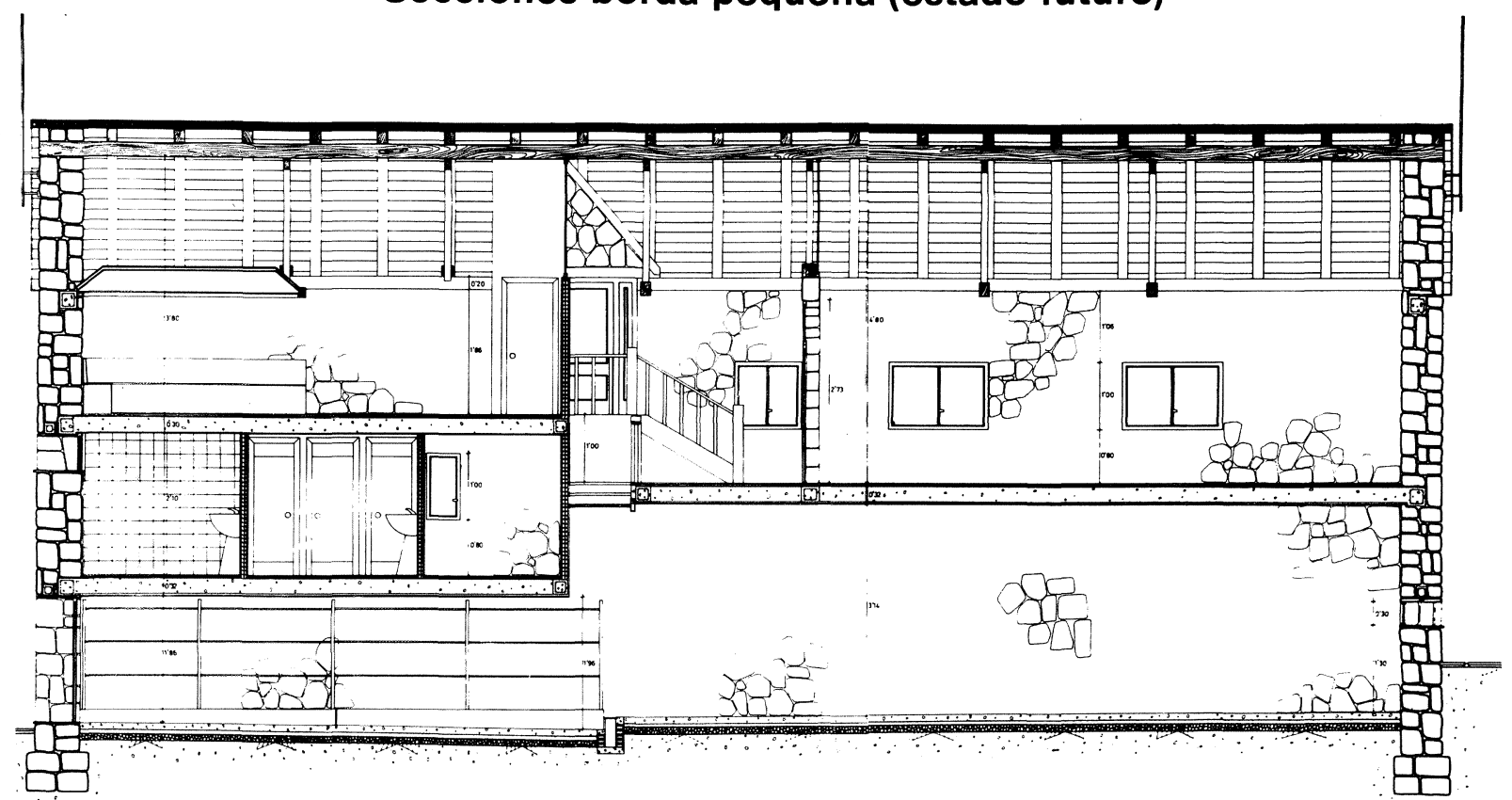

\section{Sección A-A (borda grande estado futuro)}

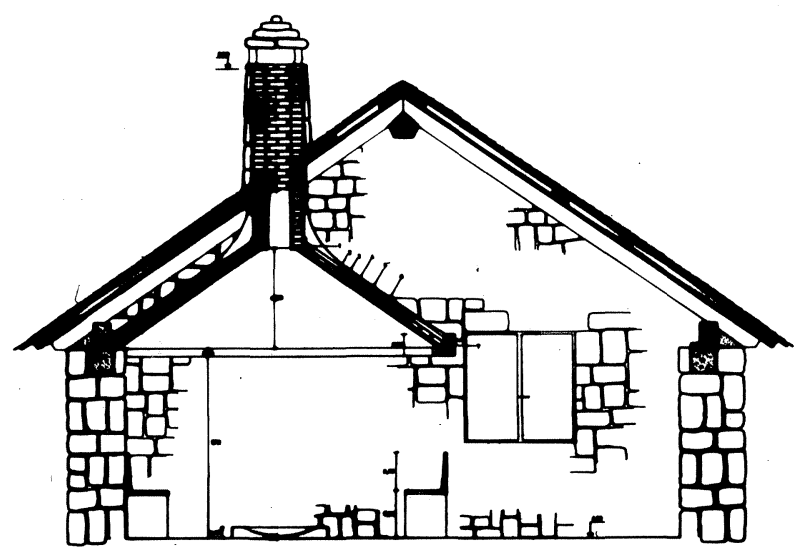

Sección de la chimenea
1.-Angular $100 \times 100 \times 14$. 2.- Perfil compuesto por chapas soldadas de $100 \times 100 \mathrm{~mm}$. 3.-Enfoscado de mortero refractario. 4. - Ladrillo macizo refractario. 5. - Enfoscado. 6. - Perfil en T $100 \times 60 \times 8$ 8. 7.-Perfil angular $100 \times 70 \times 14$. 


\section{Replanteo de escalera}

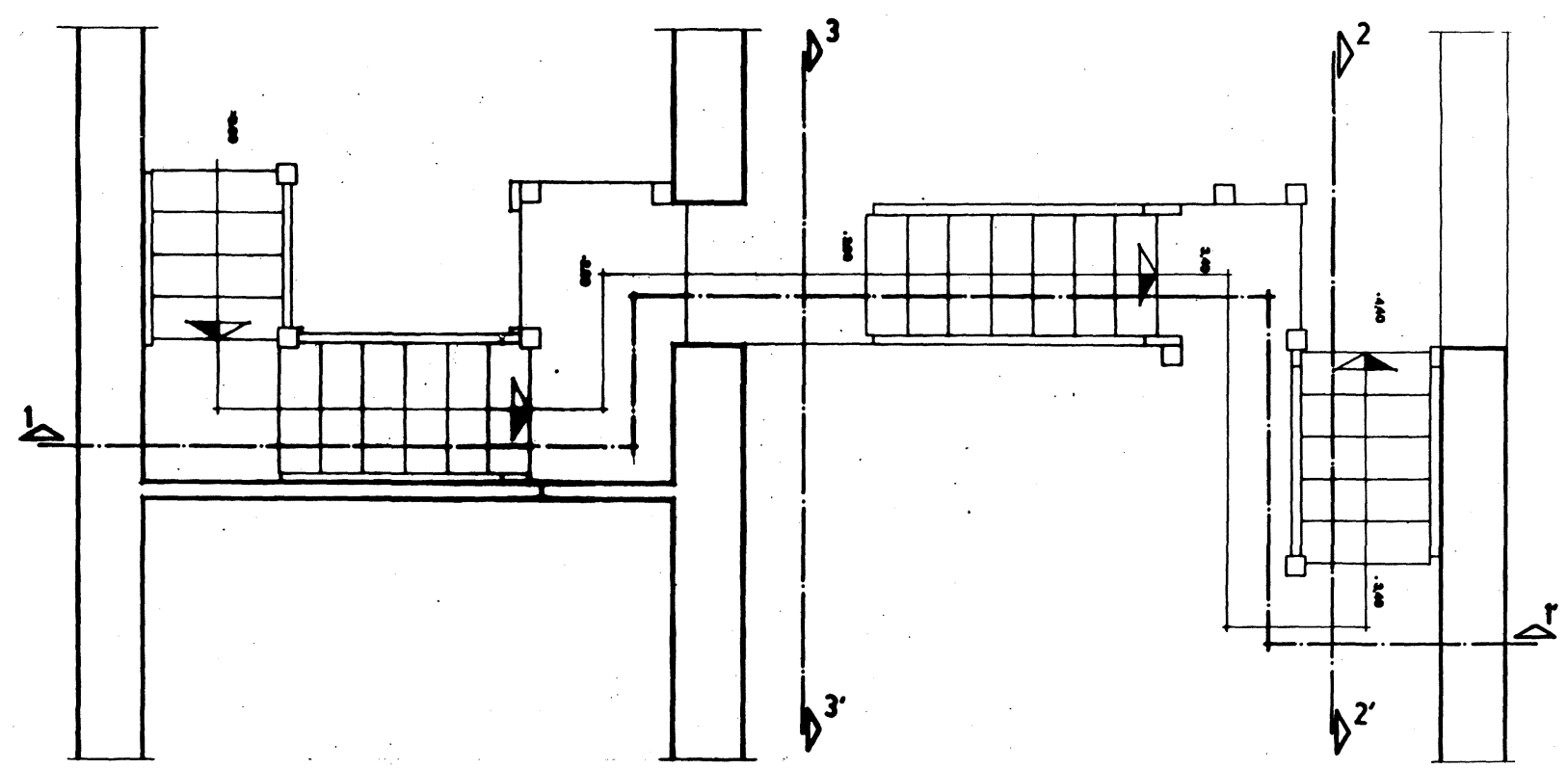

Planta de escalera

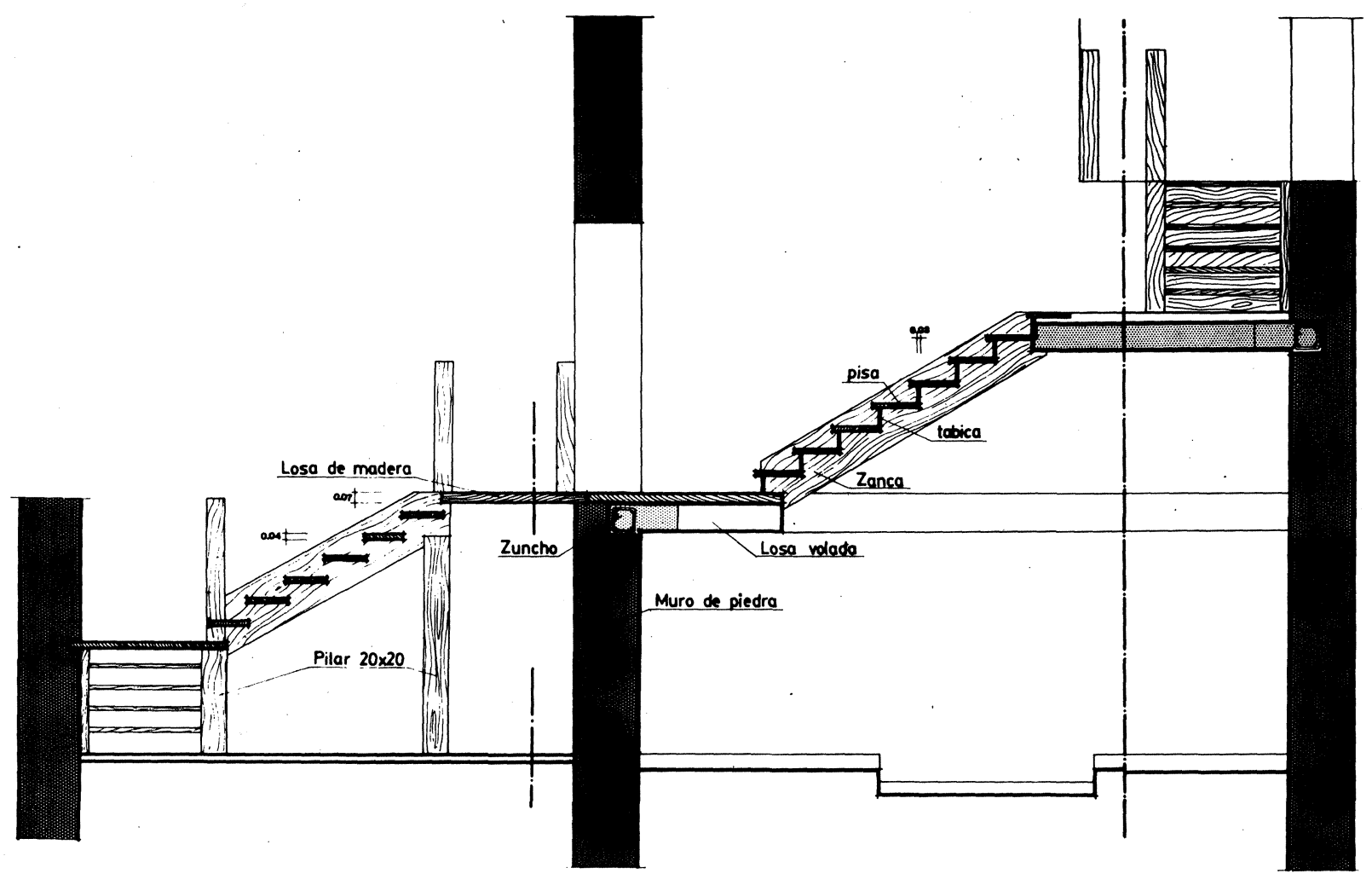

\section{Sección 1-1}




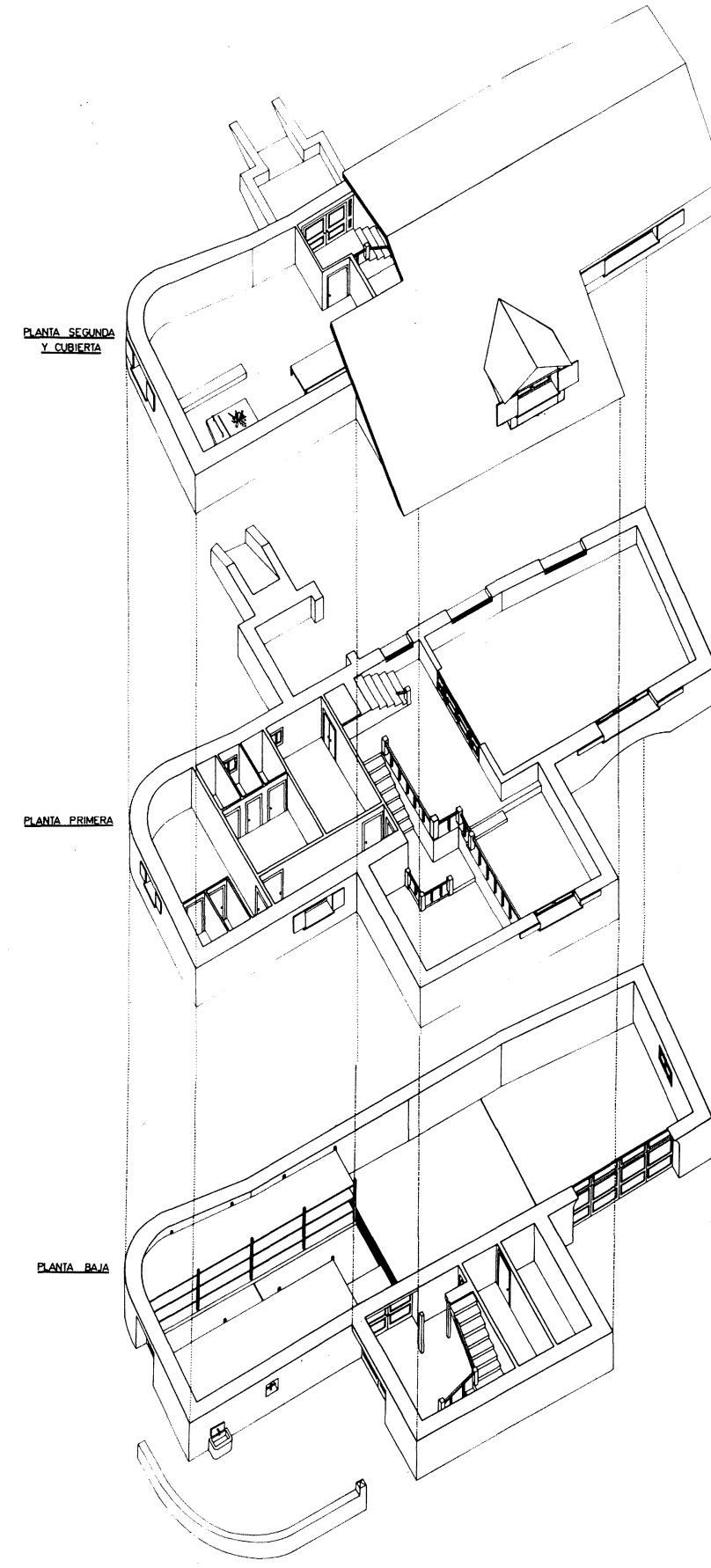

La escalera, en su totalidad de madera, se sustenta en zancas y losas, y como se puede apreciar se estudió su colocación en base a dividir la borda mediante este ancho hueco de paso.

En la planta baja se hubo de acondicionar un pasillo para evitar la cabezada con el forjado de la planta primera.
Se ha habilitado en el adosado una buhardilla a modo de mirador hacia el embalse.

En la nueva estructura de cubierta se han mantenido las estructuras anteriores, es decir, el conjunto de cercha de tijera, zapatera, parecillos e hilera.

Todo en madera de la comarca y perfectamente dimensionado.

Para obtener el coeficiente $" \mathrm{~K}_{\mathrm{g}}$ " de acondicionamiento térmico se hubo de aislar la cubierta, en ambos edificios, mediante aislante especificado y con doble tablero de madera.

Se han dispuesto huecos de paso en forma de arcos rebajados, bastante utilizados anteriormente en casas y otras construcciones.

Las bordas no eran dignas de tales adornos pero consideramos que un club deportivo, además de funcional, debia ser bello.

Como rehabilitación y a modo de prevención se estudió la construcción de un drenaje perimetral que finalmente se colocó en la zona de muro donde afectaba el nivel freático, trabajando de defensa a modo de una cámara bufa e impidiendo el contacto del agua con las paredes.

Se estudió la seguridad, sobre todo en el desmontado de cubierta y en el rejuntado, debido a la considerable altura de $12 \mathrm{~m}$ que para una construcción sin apenas medios mecánicos ya es considerable.

Un grave problema seria la traida de la red de energia eléctrica, la red de alcantarillado y evacuación y la red de agua corriente.

$\mathrm{Al}$ estar estos edificios fuera del núcleo del pueblo, estas redes de abastecimiento se cortan mucho antes de llegar a estos edificios.

La red de evacuación se ha solucionado con una fosa séptica.

La red eléctrica y de agua corriente vienen subterráneamente.

Para la subida de embarcaciones se hizo el estudio de una rampa del embalse a la borda grande tras un levantamiento topográfico de la zona de subida.

Es el deseo de todos que algún día veamos hecho realidad, si no éste, sí un futuro similar para este pueblo que nos ha marcado y que ya es un poco nuestro. 